\title{
A Comparison of the Clinical and Molecular Diagnosis of Herpes Simplex Keratitis
}

\author{
Victoria E. McGilligan1, Jonathan E. Moore1,2, Mohammad Tallouzi'3, Sarah D. Atkinson1, \\ Hugh O’Neill', Susan Feeney4, Elena S. Novitskaya5, Anant Sharma',5, Sunil Shah1,3,6, \\ Jonathan A. Jackson7 ${ }^{7}$ David G. Frazer ${ }^{7}$, Tara C. B. Moore ${ }^{1 *}$ \\ ${ }^{1}$ Centre for Molecular Biosciences, University of Ulster, Coleraine, N. Ireland \\ ${ }^{2}$ Department of Ophthalmology, Belfast Health and Social Care Trust, Mater Hospital, Belfast, N. Ireland \\ ${ }^{3}$ Birmingham and Midland Eye Centre, City Hospital, Birmingham, UK \\ ${ }^{4}$ Regional Virology Laboratory, Belfast Health and Social Care Trust, The Royal Victoria Hospital, Belfast, N. \\ Ireland \\ ${ }^{5}$ Department of Ophthalmology, Moorfields at Bedford Hospital, Bedford, UK \\ ${ }^{6}$ School of Life Sciences, University of Aston, Birmingham, UK \\ ${ }^{7}$ Department of Ophthalmology, Belfast Health and Social Care Trust, The Royal Victoria Hospital, Belfast, N. \\ Ireland \\ Email: ${ }^{*}$ t.moore@ulster.ac.uk
}

Received 1 June 2014; revised 2 July 2014; accepted 21 July 2014

Copyright (C) 2014 by authors and Scientific Research Publishing Inc.

This work is licensed under the Creative Commons Attribution International License (CC BY).

http://creativecommons.org/licenses/by/4.0/

c) (†) Open Access

\section{Abstract}

Purpose: To compare the clinical and molecular diagnoses of Herpes Simplex Keratitis (HSK). Materials and Methods: Conjunctival swabs (after fluorescein and anaesthetic wash out) and detailed questionnaire data were obtained from 146 participants. Corneal rims and conjunctival epithelial cells were infected with Herpes Simplex Virus (HSV) type 1 or HSV2 and supernatant collected. HSV1; HSV2; Varicella Zoster Virus (VZV) and Adenovirus (ADV) DNA was assessed using two real time Polymerase Chain Reaction (PCR) methods. Results: Of the 146 participants recruited, 54 were clinically diagnosed with typical epithelial lesions and 38 with atypical epithelial lesions, 17 with old inactive HSK and 37 healthy volunteers. HSV1 DNA was detected in $28(30 \%)$ of the 92 participants with clinically suspect HSK. Patients who presented with typical epithelial lesions had a higher positive rate $(46 \%)$ than those who presented with atypical type lesions (8\%), when using primers against the Glycoprotein (Gp) $G$ region of the virus. When the same samples were retested with primers against the $\mathrm{GpB}$ region, the positive rate for the typical and atypical cases increased to $52 \%$ and $11 \%$ respectively. Antiviral use at the time of sampling reduced the rate of PCR positivity by $20 \%(\mathrm{p}<0.05)$. ADV DNA was detected in $6 \%$ of the typical cases and $8 \%$ of the atypical cases. All control participants with no history of HSK were negative for HSV1 DNA. Sample quantity was confirmed by testing for housekeeping control genes, beta-actin and beta-2 macrog-

\footnotetext{
${ }^{*}$ Corresponding author.
}

How to cite this paper: McGilligan, V.E., Moore, J.E., Tallouzi, M., Atkinson, S.D., O'Neill, H., Feeney, S., Novitskaya, E.S., Sharma, A., Shah, S., Jackson, J.A., Frazer, D.G. and Moore, T.C.B. (2014) A Comparison of the Clinical and Molecular Diagnosis of Herpes Simplex Keratitis. Open Journal of Ophthalmology, 4, 65-74. http://dx.doi.org/10.4236/ojoph.2014.43011 
lobulin. PCR results from in vitro control investigations of HSV1 and 2 infected corneal rims and conjunctival epithelial cells were $100 \%$ positive for infected and $100 \%$ negative for uninfected samples when assessed using both PCR methods. Conclusions: Clinical diagnosis of typical HSK is not always confirmed by PCR. Concomitant use of an antiviral reduces levels of PCR positivity. Given this and the findings that other ocular surface pathogens may mimic HSK pathology, and that choice of gene amplification region can also affect accurate detection of HSV1 by PCR, we propose the use of a multiplex assay. This would perform PCR using primers spanning a number of different regions within one gene and would also target a number of different viral genes to ensure potentially different HSV1 viral strains or other viruses do not affect the test and lead to disagreements between the clinical and molecular diagnosis of HSK. From these findings, this paper proposes a clinical supportive algorithmic guide to manage such disagreements.

\section{Keywords}

Herpes Simplex Keratitis, PCR, Antivirals, Viralgenotype

\section{Introduction}

The predominant cause of infectious corneal blindness in the developed world is Herpes Simplex Virus type 1 (HSV1) infection of the eye [1]. HSV1 is responsible for the development of Herpes Simplex Keratitis (HSK) and has a global incidence of up to 1.5 million people per year including 40,000 cases with severe visual impairment or blindness due to this disease [2]. Corneal scarring in recurrent HSK patients is a common sign for corneal transplantation [3], with graft rejections higher when compared to other common non-herpetic keratitis conditions [4].

At present, the diagnosis of HSK is primarily dependent on the clinical opinion of the ophthalmologist. It is a diagnostic and therapeutic challenge to the clinician and often difficult to make a correct diagnosis based only on clinical presentation. Misdiagnosis may result due to other ocular pathogens presenting with similar clinical pathologies to that of HSV1. Marangon et al. [5] reported that in their study, approximately 5\% of the clinically diagnosed cases of HSK were caused by adenovirus (ADV) and $2.7 \%$ by enterovirus rather than HSV1. They also found that $3.2 \%$ of the suspected herpes conjunctivitis cases were in fact due to cytomegalovirus (CMV). A similar study reported that Varicella Zoster Virus (VZV) was misdiagnosed as HSV1 in 8\% of patients [6]. Confirmatory or additional molecular tests are important to avoid potential lifelong inappropriate diagnosis of HSK and also to enable appropriate treatment.

Polymerase Chain Reaction (PCR) based assays are high throughput and highly sensitive for viral detection. PCR is however not without its own inherent problems, with large variations observed in various studies between the rate of HSV1 detection by PCR and the clinical diagnosis [7]-[10].

The objective of this study was two-fold, to compare the clinical diagnosis of HSK with the molecular detection of HSV1 DNA and to investigate factors that could be responsible for clinical or molecular misdiagnosis such as other viruses (ADV, VZV and HSV2), antiviral use at the time of sampling, and choice of HSV1 gene targets.

This study highlights the difficulty in HSK diagnosis and the need for future research to focus on the development of a more reliable diagnostic platform.

\section{Materials and Methods}

\subsection{Participants and Specimen Collection}

Conjunctival swabs were collected from participants attending ophthalmic emergency departments at four UK hospitals. One swab was collected from the suspected HSK infected eye (or control group eye) and one from the healthy eye of each participant; five minutes after topical anaesthesia. Samples were placed immediately into a labelled sterile (DNAse and RNAse free eppendorf) containing lysis buffer (Qiagen, Crawley, UK). Experienced ophthalmic clinicians in the ophthalmic accident and emergency departments performed clinical assessment with a detailed description of the corneal lesion and patients were asked to complete questionnaires pertaining to 
their HSK history. Questions were asked with regards to number of previous HSV1 infections, duration of present and previous infection as well as any treatments used for present and previous HSK occurrences. Immunosuppressed patients including those treated with systemic steroids were excluded from the study. Informed consent was obtained from each participant and ethical approval for this study was obtained from the Office for Research Ethics Committees Northern Ireland (ORECNI) and the study was carried out in accordance with the declaration of Helsinki.

\subsection{Real Time PCR}

DNA was extracted from swabs with a commercially available QIAamp mini kit (Qiagen, Crawley, UK). For LightCycler multiplex real time PCR the amplification regions for PCR were the HSV1 glycoprotein G gene, HSV2 glycoprotein D gene, and the VZV DNA polymerase gene [11] [12]. All samples were re-analysed for the ADV hexon gene [13]. Table 1 details the primer and probe sequences used. PCR was performed using the following clinical validated protocol: one cycle at $50^{\circ} \mathrm{C}$ for 15 minutes and 1 cycle at $95^{\circ} \mathrm{C}$ for 5 minutes, 45 cycles at $95^{\circ} \mathrm{C}$ for 15 seconds, and at $60^{\circ} \mathrm{C}$ for 1 minute and 1 cycle at $40^{\circ} \mathrm{C}$ for 20 seconds. All PCR reactions were performed in a LightCycler 480, (Roche, Burgess Hill, UK) in a regional clinical diagnostic laboratory (Regional Virology Laboratory, Royal Victoria Hospital, Belfast).

Samples were re-analysed by real time PCR in a standard research laboratory using the commercially available artus HSV1/2 LC PCR kit (Qiagen, Crawley, UK) according to the manufacturer's instructions on a LightCycler 2.0 (Roche, Burgess Hill, UK). The amplification target for this PCR was the HSV1 glycoprotein B gene. All samples and the negative and positive controls were performed in duplicate. Sample quality was tested using primers against the $\beta$-actin and beta- 2 macroglobulin housekeeping control genes.

\subsection{HSV1 Infection of the Spontaneously Immortalized Epithelial Cell Line from Normal Human Conjunctiva (IOBA-NHC) and Human Donor Corneal Rims and Real Time PCR Titration Experiments}

Initial experiments demonstrated a large percentage of PCR negative results for HSV1 in samples clinically diagnosed as typical HSK. Experiments were therefore designed to test the possibility of false negative results. HSV1 (obtained from the Regional Virus Laboratory, Belfast Health and Social Care Trust, Belfast) was titrated and tested by real time PCR to achieve a concentration similar to that found in HSV1 PCR positive clinical samples (cycle threshold 22) and to ascertain the lowest concentration of detection for both PCR methods. HSV1 was titrated from $1 \times 101 \mathrm{ml}$ to $1 \times 1010 \mathrm{ml}$ and tested by the PCR methods described above. Conjunctival epithelial cells (IOBA-NHC; kindly donated by the Institute of Applied Ophthalmobiology, University of Valladolid, Spain) and donor corneal rims (CTS Eye Bank, Manchester, UK) were cultured in growth media: Dulbecco's Modified Eagle’s Medium: F12 (1:1) + L-Glutamine + 15mM Hepes, 10\%, Foetal Bovine Serum (FBS) (all Life Technologies, Paisley, UK), 10ng/ml Epidermal Growth Factor, 5 g/ml Insulin, 0.1 ug/ml Cholera Toxin, $0.5 \%$ Hydrocortisone, and 1\% Penicillin/Streptomycin (all Sigma-Aldrich, Dorset, UK). The IOBANHC cells or human corneal rims were incubated for 3 hours at $37^{\circ} \mathrm{C}$ with or without HSV1 or HSV2 to estab-

Table 1. Primers and probes.

\begin{tabular}{|c|c|c|c|}
\hline Virus & Gene & Primer and Sequence & Refs \\
\hline HSV1 & GpG & $\begin{array}{l}\text { HSV1 12A 5'-TCCTSGTTCCTMACKGCCTCCC-3' } \\
\text { HSV1 12B 5'-GCAGICAYACGTAACGCACGCT-3' } \\
\text { HSV1 12P 5'-FAM-CGTCTGGACCAACCGCCACACAGGT-3'TAMRA }\end{array}$ & $\begin{array}{c}\text { van Doornum et al. } 2003 \\
\text { [11] }\end{array}$ \\
\hline HSV2 & GpD & $\begin{array}{l}\text { HSV1 3A 5'-CGCCAAATACGCCTTAGCA-3' } \\
\text { HSV1 3B 5'-GAGGTTCTTCCCGCGAAAT-3' } \\
\text { HSV1 3P 5'-FAM-CTCGCTTAAGATGGCCGATCCCAATC-3'TAMRA }\end{array}$ & $\begin{array}{c}\text { van Doornum et al.2003 } \\
{[11]}\end{array}$ \\
\hline VZV & $\begin{array}{c}\text { DNA } \\
\text { polymerase }\end{array}$ & $\begin{array}{l}\text { VZV 4A 5'-CGGCATGGCCCGTCTAT-3' } \\
\text { VZV 4B 5'-TCGCGTGCTGCGGC-3' } \\
\text { VZV 4P 5'-6FAM-ATTCAGCAATGGAAACACACGACGCC-BHQ-3' }\end{array}$ & $\begin{array}{c}\text { Weidmann et al. } 2008 \\
\text { [12] }\end{array}$ \\
\hline $\mathrm{ADV}$ & Hexon & $\begin{array}{l}\text { ADV 3A 5'-GCCACGGTGGGGTTTCTAAACTT-3' } \\
\text { ADV 3B 5'-GCCCCAGTGGTCTTACATGCACATC-3' } \\
\text { ADV 3P 3'-FAM-TGCACCAGACCCGGGCTCAGGTACTCCGA-BHQ-5', }\end{array}$ & Heim et al. 2003 [13] \\
\hline
\end{tabular}


lish infection and then maintenance media (growth media with 2\% FBS) was added and cells and rims were incubated for a further 20 hours. Samples were collected every day for eight days by wiping a swab across the cell surface and placing them immediately into sterile DNase/RNase free eppendorfs containing lysis buffer to mimic the ocular surface clinical sampling method and then analysed by both real time PCR methods; as described above.

\subsection{Statistical Analysis of Data: Comparison of the Clinical and Molecular Diagnosis of HSK, Analysis of Antiviral Effect on PCR Results and Analysis of the Effect of Duration of Patient Symptoms on PCR Results}

Descriptive statistics were performed using SPSS version 18.0. The Kappa coefficient of variation was used to determine agreement between the diagnosis made by the clinician and PCR results obtained with a p value < 0.001 considered to be statistically significant. This statistical method is used to assess the degree to which two or more raters, examining the same data, agree when it comes to assigning the data to categories. The Chi-Square test was used to determine any statistically significant relationship between antiviral use and PCR result or duration of patient symptoms prior to sampling and PCR result with a p value $<0.05$ considered to be statistically significant.

\section{Results}

\subsection{Clinical Diagnosis of Study Cohort}

The total participant number in this study was 146 with an age range of between 18 and 90 years and a mean age of 48 years. Table 2 details the clinical diagnosis made by the ophthalmologist for each participant grouped by clinical presentation. The study cohort consisted of 58 participants with evidence of epithelial disease, 26 participants with stromal and epithelial disease and 8 participants with stromal disease only. Seventeen old HSK cases (previous history of HSK but not thought to be disease active) and 37 healthy control participants were also recruited. From these disease type groupings, participants were then further divided into two main groups; Group 1 were patients who presented with typical signs of HSK n = 54, (evidence of dendritiform lesions Figure 1)

Table 2. HSK classification according to clinical diagnosis and PCR result.

\begin{tabular}{ccc}
\hline Clinical Diagnosis & No. Patients $(\mathrm{n}=146)$ & No. of patients with positive PCR $(\mathrm{n}=28)$ \\
\hline Epithelial & 58 & 20 \\
Stromal and Epithelial & 26 & 8 \\
Stromal & 8 & 0 \\
Old HSK & 17 & 0 \\
Healthy/Other & 37 & 0 \\
\hline
\end{tabular}

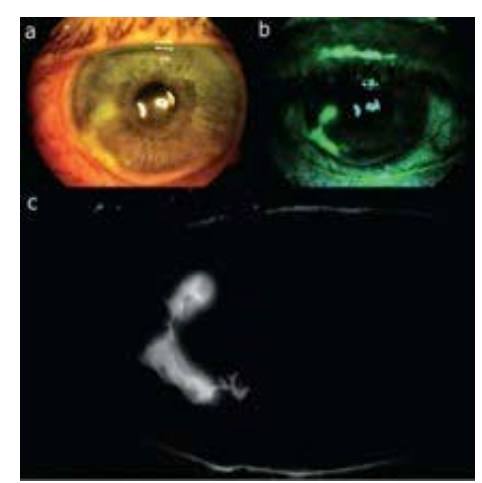

Figure 1. Clinical presentation of a suspected case of typical. HSK Herpes Simplex Virus dendritic ulcer following application of fluorescein: (a) white light photograph; (b) blue $(488 \mathrm{~nm})$ exciter filter; and (c) exciter and barrier filters in place. Photographs were taken with the digital fundus camera (FF 450 Plus IR, Carl Zeiss Meditec, Jena, Germany. This case tested PCR positive for HSV1. 
and Group 2 were patients who presented with atypical signs of HSK n = 38 (no evidence of dendritiform lesions but with various other indicative clinical signs of HSK). Both groups consisted of patients suspected as having primary or recurrent HSK.

\subsection{Comparison between the Clinical and the Molecular Diagnosis of HSK}

The samples obtained from all participants were analysed in the Regional Virology laboratory at the Royal Victoria Hospital in Belfast, using primers to amplify the GpB region of the virus. HSV1 DNA was detected in 28 (30\%) of the 92 patients that presented with a positive clinical diagnosis of active HSK. A significantly higher PCR positive rate was obtained for those patients that presented with typical epithelial type lesions (25 patients-46\%) as compared to those that presented with atypical type lesions ( 3 patients-8\%) ( $p=0.00015$; Table 3).

Factors responsible for the discrepancy between the clinical and molecular diagnosis of HSK were then investigated.

Retesting of the samples in a standard research laboratory using primers to amplify the GpB region of the virus instead of GpG, increased the PCR positive rate to 28 (51\%) patients and 4 (10\%) patients for the typical and atypical cases respectively (Table 3).

Additional factors including antiviral use at the time of sampling, duration of patient symptoms and other ocular surface infections were investigated for the differences observed between the clinical and molecular diagnostic methods. HSV1 PCR positive rates were greater in the patients who presented with typical corneal epithelial lesions that did not previously use an antiviral ( $\mathrm{p}=0.022$; Table 4). In patients who presented with atypical lesions previous or concurrent use of an antiviral did not seem to impact upon the likelihood of a positive PCR result $(\mathrm{p}=0.968$; Table 4$)$. The duration of symptoms did not appear to make any statistically significant difference between the HSV1 PCR positive rates in those who presented with either typical or atypical lesions ( $p$ $=0.808$ and $\mathrm{p}=0.823$ respectively; Table 5 ).

Table 3. HSV1 PCR result for patients presenting typical or atypical epithelial lesions and comparison of two different PCR methods: For the LightCycler nested multiplex real time PCR, a fully validated method in a clinical hospital laboratory, the ampli-fication region was HSV1 glycoprotein G gene; For the LightCycler real time PCR using the Qiagen artus HSV1LC PCR kit in a re-search laboratory, the amplification target was the HSV1 glycoprotein B gene.

\begin{tabular}{|c|c|c|c|c|c|c|}
\hline & & \multicolumn{5}{|c|}{ HSV1 PCR result } \\
\hline & & \multirow{2}{*}{\multicolumn{2}{|c|}{$\begin{array}{c}\text { Hospital laboratory Method } \\
\text { Amplification target: GpG }\end{array}$}} & \multicolumn{2}{|c|}{ Research laboratory Method } & \multirow[b]{3}{*}{ Total } \\
\hline & & & & Amplificat & rget GpB & \\
\hline & & Positive & Negative & Positive & Negative & \\
\hline Clinical & Typical epithelial lesion & $25(46)$ & $29(54)$ & $28(52)$ & $26(48)$ & $54(100) \mathrm{p}=0.625^{* *}$ \\
\hline Presentation: & Atypical epithelial lesion & $3(8)$ & $35(92)$ & $4(11)$ & $34(90)$ & $38(100)$ \\
\hline \multirow[t]{2}{*}{ Total } & & $27(29)$ & $65(71)$ & $32(35)$ & $60(65)$ & $92(100)$ \\
\hline & & \multicolumn{2}{|c|}{$\mathrm{p}=0.00015^{*}$} & \multicolumn{2}{|c|}{$\mathrm{p}=0.00004^{*}$} & \\
\hline
\end{tabular}

Data reported as n (frequency, \%). ${ }^{*}$ Pearson chi-square test for any significant difference between clinical presentation and the HSV1 PCR result. ${ }^{* *}$ Pearson chi-sqaure test for any significant difference between PCR methods and the HSV1 PCR result.

Table 4. Antiviral use and HSV1 PCR result for patients with typical and atypical clinical presentations.

\begin{tabular}{ccccccc}
\hline & & \multicolumn{2}{c}{ HSV1 positive } & \multicolumn{2}{c}{ HSV1 negative } & \\
\cline { 3 - 6 } & & Antiviral & No Antiviral & Antiviral & No Antiviral & Total \\
\hline Clinical & Typical epithelial lesion & $4(7)$ & $24(44)$ & $11(20)$ & $15(28)$ & $54(100) \mathrm{p}=0.022^{*}$ \\
Presentation: & Atypical epithelial lesion & $1(2)$ & $3(8)$ & $8(21)$ & $26(68)$ & $38(100) \mathrm{p}=0.948^{*}$ \\
Total & & $5(5)$ & $27(29)$ & $19(20)$ & $41(45)$ & $92(100)$ \\
\hline
\end{tabular}

Data reported as n (frequency, \%). *Pearson chi-square test for any significant difference between antiviral use and HSV1 PCR result for patients with typical or atypical clinical presentations. 
Table 5. Symptom duration and HSV1 PCR result for patients with typical and atypical clinical presentations.

\begin{tabular}{|c|c|c|c|c|c|c|}
\hline & \multicolumn{3}{|c|}{ Typical epithelial lesion HSV1 PCR } & \multicolumn{3}{|c|}{ Atypical epithelial lesion HSV1 PCR } \\
\hline & Positive & Negative & Total & Positive & Negative & Total \\
\hline Symptoms $>1$ week & 12 & 12 & & 2 & 15 & \\
\hline Symptoms $<1$ week & 16 & 14 & & 2 & 19 & \\
\hline \multirow[t]{2}{*}{ Total } & 28 & 26 & 54 & 4 & 34 & 38 \\
\hline & \multicolumn{2}{|c|}{$p=0.808^{*}$} & & \multicolumn{2}{|c|}{$* p=0.823$} & \\
\hline
\end{tabular}

Data reported as n. *Pearson chi-square test for any significant difference between symptom duration and HSV1 PCR result.

Three (6\%) of the patients who presented with typical epithelial type lesions and 3 (8\%) who presented with atypical epithelial type lesions tested positive for ADV DNA (Table 6). The type of lesion (typical or atypical) had no significant affect on ADV PCR incidence.

These results demonstrate an agreement level of only 46\% (25 patients PCR positive for HSV1 DNA) between the clinical and molecular diagnosis of patients presenting with typical HSK epithelial lesions. This was calculated using the PCR results from the fully validated method in the Regional Virology hospital laboratory. Statistical analysis using the Kappa co-efficient of variation to compare the clinical diagnosis of the typical cases of HSK with molecular PCR diagnosis, demonstrate this as only a moderate level of agreement between both diagnostic techniques (kappa $=0.485$, $\mathrm{p}<0.0001$ ). Even after consideration of the PCR method, using a different HSV1 glycoprotein amplification region, antiviral usage and ADV infection, 12 (22\%) of the 54 patients who presented with typical epithelial type lesions but who tested negative for HSV1 DNA, were left without a definitive diagnosis. These 12 patients were prescribed an antiviral and upon follow up, 8 were relieved of symptoms and the lesion.

\subsection{Control Samples}

All samples taken from participants with old cases of HSK thought not to be disease active, tested negative for HSV1 DNA, however two participants tested positive for ADV DNA. Likewise all samples taken from age and sex matched control non-HSK participants tested negative for HSV1 DNA and two participants tested positive for ADV DNA. All study participants, both controls and the suspected cases of HSK, tested negative for HSV2 and VZV DNA and no participants were positive for more than one virus type.

\subsection{Sample Quantity and PCR Sensitivity}

Samples from all participants were positive for the $\beta$-actin and beta 2-macroglobulin housekeeping control genes. In vitro sampling and analysis by real time PCR against the GpG and GpB genes confirmed that $100 \%$ of all conjunctival epithelial cells (IOBA-NHC cells) and human donor corneal rims infected with HSV1 or HSV2, at a concentration comparable to that detected in clinical samples, tested PCR positive for the respective virus and $100 \%$ uninfected controls tested negative. Titration experiments were carried out to test the sensitivity of both PCR assays and the results obtained demonstrated that both systems could detect HSV1 at a concentration of 1x108 times less concentrated than the concentration of virus found in a typical HSK clinical sample.

\section{Discussion}

The present study compares the clinical diagnosis of HSK to PCR diagnosis and highlights the differences in diagnostic results dependent on the test used.

The diagnosis of HSK can at times pose difficulties to both experienced and novice clinicians. It is usually thought however, that the classic dendritiform epithelial lesion is pathognomonic. There are significant implications from misdiagnosis, both from false negative and false positive, with the possibility of increased morbidity due to delay in appropriate antiviral treatment and the consequences of a possible life long diagnosis of HSK.

This study demonstrated as expected that the PCR positive rate of HSV1 incidence was higher in those patients who presented with typical epithelial lesions as compared to those who presented with atypical type lesions ( $<<0.001)$. However, surprisingly there was still only a moderate level of agreement between the clinical 
Table 6. ADV PCR result for clinically suspect cases of HSK that tested negative for HSV1 by PCR.

\begin{tabular}{ccccc}
\hline & & \multicolumn{3}{c}{ ADV PCR result } \\
\cline { 3 - 4 } Clinical presentation: & Typical epithelial lesion & Positive & Negative & Total \\
& Atypical epithelial lesion & $3(6)$ & $51(94)$ & $54(100) \mathrm{p}=0.655^{*}$ \\
Total & & $3(8)$ & $35(92)$ & $38(100)$ \\
& & $6(7)$ & $86(93)$ & $92(100)$ \\
\hline
\end{tabular}

Data reported as n (frequency, \%). ${ }^{*}$ Pearson chi-square test for any significant difference between clinical presentation and ADV PCR result.

and molecular diagnosis (kappa statistic $=0.485$, $\mathrm{p}<0.0001$ ) where there was a typical HSK epithelial dendritiform ulcer defined by the clinician. HSV1 DNA was detected in 25 (46\%) participants who presented with typical dendrite appearance, leaving 29 (54\%) without a definitive diagnosis. This finding is in keeping with several other PCR HSK diagnostic studies [7]-[10], demonstrating a range in agreement between the opinion of the clinician and PCR of $30 \%$ to $88 \%$ in the suspected HSK cases.

The PCR system used in this study was chosen as it was previously proven to be highly sensitive and specific and used within a routine regional diagnostic virology laboratory to detect low levels of viral DNA. Specificity and sensitivity were further confirmed in the present study through in vitro and ex vivo laboratory HSV1 infection, at a concentration similar to that found in clinical isolates. In addition, the presence of DNA for two housekeeping genes was detected for all samples tested on the same PCR machine indicating substantial sample quantity.

Our investigations highlight several factors that could explain some of the variation observed between both diagnostic techniques. We found that when the same samples were reanalysed in a standard research laboratory using primers against a different amplification region of the gene, HSV1 DNA was detected in an additional 6 patients (Table 2). Three of which presented with typical epithelial lesions and 3 with atypical type lesions. This study therefore demonstrated $4 \%$ to $6 \%$ variability between two similar PCR methods.

However, when these two PCR methods were used to test in vitro infected HSV1 cells and ex vivo infected corneal rims at a concentration similar to that found in clinical samples, no difference in results were obtained. Importantly in the in vitro experiments, only one viral strain was tested and various herpes viral strains have been detected in clinical isolates and mutations in these strains have been evidenced [14]-[16]. Phylogenetic analysis in a more recent study demonstrated that gene sequences from well-defined clinical HSV1 isolates could be separated into 3 to 6 distinct genogroups [17] [18]. The assumed conserved region used for primer choice may be prone to mutations and variations in viral isolates due to the fact that glycoproteins are notoriously involved in evasion strategies to avoid the immune system of the host [19]. Choice of HSV1 gene amplification region may therefore play a key role in explaining the variability between the clinical and molecular methods.

Statistical analysis also revealed that antiviral use was associated with a PCR negative result for those patients presenting with typical lesions ( $\mathrm{p}=0.02$; Table 3). Wald et al. 1997 [20] previously reported that HSV DNA rapidly disappeared from mucosal surfaces when acyclovir was taken in dosages of $400 \mathrm{mg}$ twice daily. This previous study demonstrated an $80 \%$ reduction of detectable virus when patients who had been shedding virus (as tested by both viral culture and PCR) were on antiviral medication. The current results are therefore in keeping with previous studies and suggest that the use of an antiviral at the time of sampling can reduce PCR sensitivity below the level of detection.

Six of the 26 HSV1 negative patients were positive for the presence of ADV DNA (Table 5), 3 (6\%) presented with typical lesions and 3 (8\%) with atypical lesions. In the current study, in each of the 6 cases confirmed positive for ADV DNA, the virus was only detected in the affected eye. Previous studies also presented similar findings providing evidence that other ocular surface pathogens such as ADV, CMV, VZV or enterovirus [5] [6] or infections like keratomycosis and pseudokeratitis [21] [22] may be a possible cause of HSK misdiagnosis since they present with a similar clinical pathology.

After consideration of PCR method, gene amplification region, antiviral use and other ocular surface infections, 12 patients (22\%) in this study who presented with typical epithelial type lesions but who tested negative for HSV1 DNA were left without a definitive diagnosis.

Experienced clinicians examined all patients and observed typical or atypical dendritic lesions consistent with HSK. Figure 1 is an example of a typical case identified during this study. Eight of the remaining 12 patients, who were diagnosed with typical HSK but tested PCR negative for HSV1, were prescribed acyclovir and a fol- 
low up investigation demonstrated a positive response. However, this treatment or indeed any lubricating ointment could have aided the healing of most conditions since they are usually self-limiting and heal with time. So although the positive response to the antiviral does point to potential correct clinical diagnosis it is not possible to confirm this.

Time between initial infection and sampling has been eliminated as a factor affecting the PCR results. The current study showed no statistically significant relationship between duration of symptoms and PCR result ( $\mathrm{p}>$ 0.80). A previous study [23] demonstrated the retention of herpetic DNA in all layers of the cornea for at least 90 days post infection and well into the latency period, therefore sampling time post initial infection should not be a reason for lack of herpetic DNA detection.

It is also important to note that local anaesthetic was used prior to swab sampling of tears and conjunctiva given that this may also impact on PCR result obtained. Goldschmidt et al. 2006 [24] reported that the introduction of topical anaesthetics and use of fluorescein into tubes containing specimens to be tested by PCR reduced the PCR detection capacities by more than 2 logs (DNA copies/sample), leading to false negative results. In this present study however, a period of at least 5 minutes was left between applications and sampling. Most of the anesthetic solution should therefore have been removed from the ocular surface by blinking, Additionally, sample quality was tested using primers against the $\beta$-actin and beta- 2 macroglobulin housekeeping control genes which confirmed PCR detection in all samples and ruled out Taq polymerase inhibition.

Even though the present study found that 34 (90\%) of the 38 patients who presented with atypical HSK tested negative for HSV1 DNA this is in keeping with other studies [25] [26]. Atypical presentations of HSK are common and difficult to diagnose and stromal keratitis is often associated with either herpes viral reactivation and/or immune response with no active virus present [27]. The latter may indeed explain some of the positive clinical yet negative PCR diagnosis observed.

In conclusion, this study demonstrates difficulties with confirmation of the clinical diagnosis of active HSK with real time PCR. The results highlight the need for the development of a more robust molecular point of care test potentially in the form of a diagnostic chip that could detect several regions/variations of the viral genome and other viruses. When a disagreement presents between clinical positive diagnosis and a PCR test for the presence of HSV1, a variety of possibilities exist, one cannot simply say that the clinical result is false. It is important to work through an initial diagnostic algorithm before making a definitive diagnosis (Figure 2). This

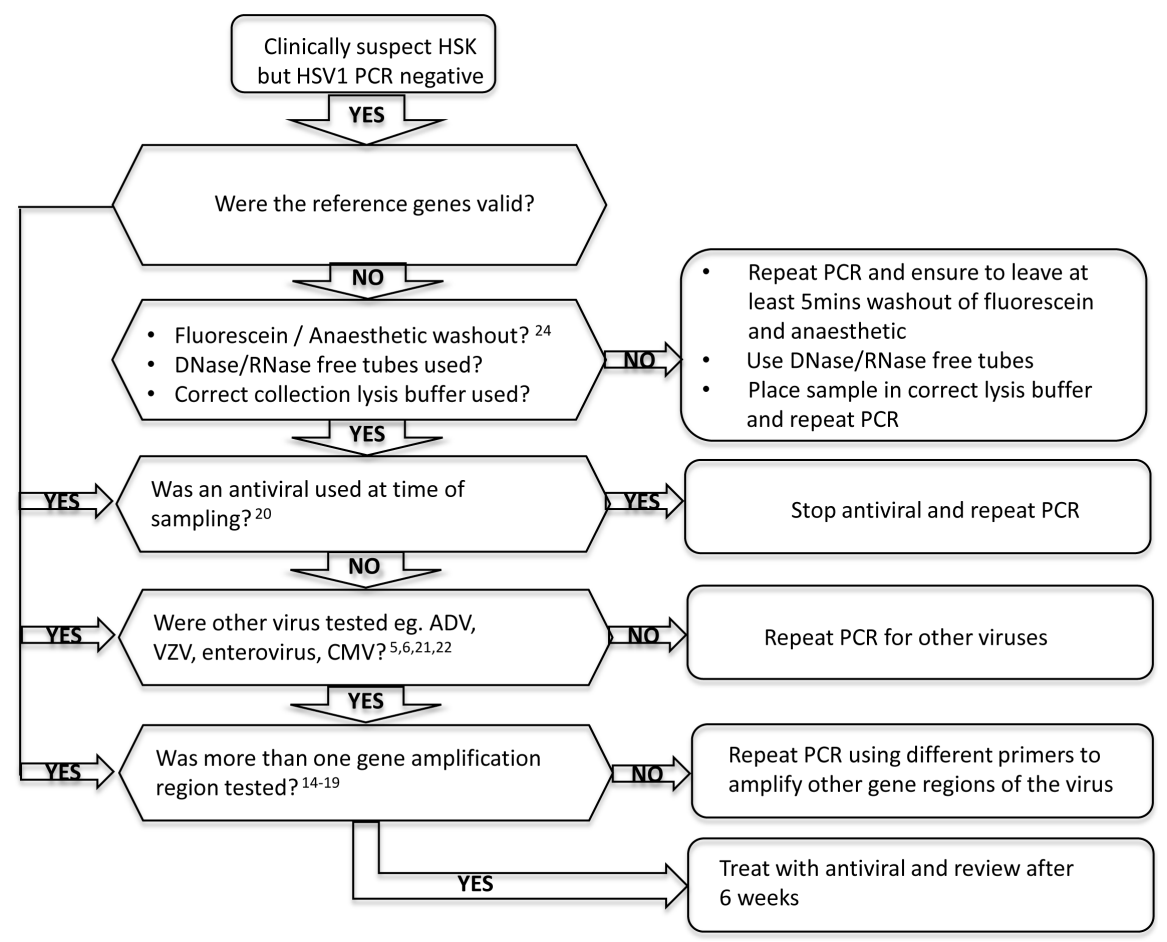

Figure 2. Clinical supportive algorithm to manage disagreements in diagnosis of typical HSK lesions, when clinical diagnosis is HSK positive but PCR diagnosis is HSV1 negative. 
should prompt ophthalmologists to consider other factors that may influence the PCR result when deciding on a final diagnosis. This may help in the early management of the disease to prevent ocular morbidity and also the possibility of an erroneous life long diagnosis of HSK with all its implications.

\section{Acknowledgements}

The authors would like to acknowledge HPSS Research and Development, Infectious Diseases Recognised research group grant 9.38 for funding this research.

\section{References}

[1] Kaye, S. and Choudhary, A. (2006) Herpes Simplex Keratitis. Progress in Retinal and Eye Research, 25, 355-380. http://dx.doi.org/10.1016/j.preteyeres.2006.05.001

[2] Farooq, A.V. and Shukla, D. (2012) Herpes Simplex Epithelial and Stromal Keratitis: An Epidemiologic Update. Survey of Ophthalmology, 57, 448-462. http://dx.doi.org/10.1016/j.survophthal.2012.01.005

[3] Al-Yousuf, N., Mavrikakis, I., Mavrikakis, E. and Daya, S.M. (2004) Penetrating Keratoplasty: Indications over a 10-Year Period. British Journal of Ophthalmology, 88, 998-1001. http://dx.doi.org/10.1136/bjo.2003.031948

[4] Halberstadt, M., Machens, M., Gahlenbek, K.A., Böhnke, M. and Garweg J.G. (2002) The Outcome of Corneal Grafting in Patients with Stromal Keratitis of Herpetic and Non-Herpetic Origin. British Journal of Ophthalmology, 86, 646-652. http://dx.doi.org/10.1136/bjo.86.6.646

[5] Marangon, F.B., Miller, D. and Alfonso, E. (2007) Laboratory Results in Ocular Viral Diseases: Implications in Clinical-Laboratory Correlation. Abo-ArquivosBrasileiros De Ofthalmologia, 70, 189-194.

[6] Rübben, A., Baron, J.M. and Grussendorf-Conen, E.I. (1997) Routine Detection of Herpes Simplex Virus and Varicella Zoster Virus by Polymerase Chain Reaction Reveals that Initial Herpes Zoster Is Frequently Misdiagnosed as Herpes Simplex. British Journal of Ophthalmology, 137, 259-261.

[7] Fukuda, M., Deai, T., Higaki, S., Hayashi, K. and Shimomura, Y. (2008) Presence of a Large Amount of Herpes Simplex Virus Genome in Tear Fluid of Herpetic Stromal Keratitis and Persistent Epithelial Defect Patients. Seminars in Ophthalmology, 23, 217-220. http://dx.doi.org/10.1080/08820530802111366

[8] Khodadoost, M.A., Sabahi, F., Behroz, M.J., Roustai, M.H., Saderi, H., Amini-Bavil-Olyaee, S. and Arzenani, M.K. (2004) Study of a Polymerase Chain Reaction Based Method for Detection of Herpes Simplex Virus 1 DNA among Iranian Patients with Ocular Herpetic Keratitis Infection. Japanese Journal of Ophthalmology, 48, 328-332. http://dx.doi.org/10.1007/s10384-004-0081-z

[9] Lee, S.Y., Kim, M.J., Kim, M.K., Wee and W.R. (2013) Comparative Analysis of Polymerase Chain Reaction Assay for Herpes Simplex Virus 1 Detection in Tear. Korean Journal of Ophthalmology, 27, 316-321. http://dx.doi.org/10.3341/kjo.2013.27.5.316

[10] Jackson, R., Morris, D.J., Cooper, R.J., Bailey, A.S., Klapper, P.E., Cleator, G.M. and Tullo, A.B. (1996) MultiplexPolymerase Chain Reaction for Adenovirus and Herpes Simplex Virus in Eye Swabs. Journal of Virological methods, 56, 41-48. http://dx.doi.org/10.1016/0166-0934(95)01903-0

[11] Van Doornum, G.J., Guldemeester, J., Osterhaus, A.D. and Niesters, H.G. (2003) Diagnosing Herpesvirus Infections by Real-Time Amplification and Rapid Culture. Journal of Clinical Microbiology, 41, 576-580. http://dx.doi.org/10.1128/JCM.41.2.576-580.2003

[12] Weidmann, M., Armbruster K. and Hufert, F.T. (2008) Challenges in Designing a Taqman-based Multiplex Assay for the Simultaneous Detection of Herpes Simplex Virus Types 1 and 2 and Varicella-Zoster Virus. Journal of Clinical Virology, 42, 326-334. http://dx.doi.org/10.1016/j.jcv.2008.03.005

[13] Heim, A., Ebnet, C., Harste, G. and Pring-Akerblom, P. (2003) Rapid and Quantitative Detection of Human Adenovirus DNA by Real-Time PCR. Journal of Medical Virology, 70, 228-239. http://dx.doi.org/10.1002/jmv.10382

[14] Sivadon, V., Lebon, P. and Rozenberg, F. (1998) Variations of HSV-1 Glycoprotein B in Human Herpes Simplex Encephalitis. Journal of Neurovirology, 4, 106-114. http://dx.doi.org/10.3109/13550289809113488

[15] Rekabdar, E., Tunbäck, P., Liljeqvist, J.A. and Bergström, T. (1999) Variability of the Glycoprotein G Gene in Clinical Isolates of Herpes Simplex Virus Type 1. Clinical and Diagnostic Laboratory Immunology, 6, 826-831.

[16] Fan, Q., Lin, E., Satoh, T., Arase, H. and Spear, P.G. (2009) Differential Effects on Cell Fusion Activity of Mutations in Herpes SimplexVirus 1 Glycoprotein B (gB) Dependent on Whether a gD Receptor or a gB Receptor Is Overexpressed. Journal of Virology, 83, 7384-7390. http://dx.doi.org/10.1128/JVI.00087-09

[17] Norberg, P., Bergström, T., Rekabdar, E., Lindh, M. and Liljeqvist, J.A. (2004) Phylogenetic Analysis of Clinical Herpes Simplex Virus Type 1 Isolates Identified Three Genetic Groups and Recombinant Viruses. Journal of Virology, 
78, 10755-10764. http://dx.doi.org/10.1128/JVI.78.19.10755-10764.2004

[18] Kolb, A.W., Ané, C. and Brandt, C.R. (2013) Using HSV-1 Genome Phylogenetics to Track Past Human Migrations. PLOS ONE, 8, e76267. http://dx.doi.org/10.1371/journal.pone.0076267

[19] Haarr, L. and Skulstad, S. (1994) The Herpes Simplex Virus Type 1 Particle: Structure and Molecular Functions. Review article. Acta Pathologica, Microbiologica, et Immunologica Scandinavica, 102, 321-346. http://dx.doi.org/10.1111/j.1699-0463.1994.tb04882.x

[20] Wald, A., Corey, L., Cone, R., Hobson, A., Davis, G. and Zeh, J. (1997) Frequent Genital Herpes Simplex Virus 2 Shedding in Immunocompetent Women. Effect of Acyclovir Treatment. Journal of Clinical Investigation, 99, 10921097. http://dx.doi.org/10.1172/JCI119237

[21] Besada, E. and Reynolds, S. (2005) Incidental Corneal Pseudodendrite Recurrence upon Reinitiation of Latanoprost. Clinical \& Refractive Optometry, 16, 233-236.

[22] Mariko, T., Yasuhisa, S., Hiroshi, S. and Kimiyo, F. (1999) Keratomcosis:Clinical diagnosis, Medical and Surgical Treatment. Journal of Medical Education and Research, 5, 3-10.

[23] Pavan-Langston, D. (1990) Herpes Simplex Virus Ocular Infections: Current Concepts of Acute, Latent and Reactivated Disease. Transactions of the American Ophthalmology Society, 88, 727-796.

[24] Goldschmidt, P., Rostane, H., Saint-Jean, C., Batellier, L., Alouch, C., Zito, E., Bourcier, T., Laroche, L. and Chaumeil, C. (2006) Effects of Topical Anaesthetics and Fluorescein on the Real-Time PCR Used for the Diagnosis of Herpesviruses and Acanthamoeba Keratitis. British Journal of Ophthalmology, 90, 1354-1356. http://dx.doi.org/10.1136/bjo.2006.098830

[25] Koizumi, N., Nishida, K., Adachi, W., Tei, M., Honma, Y., Dota, A., Sotozonao, C., Yokoi, N., Yamamotoo, S. and Kinoshita, S. (1999) Detection of Herpes Simplex Virus DNA in Atypical Epithelial Keratitis Using Polymerase Chain Reaction. British Journal of Ophthalmology, 83, 957-960. http://dx.doi.org/10.1136/bjo.83.8.957

[26] Athmanathan, S., Pranesh, V.M., Pasricha, G., Garg, P., Vemuganti, G.K. and Sharma, S. (2001) Atypical Herpes Simplex Keratitis (HSK) Presenting as a Perforated Corneal Ulcer with a Large Infiltrate in a Contact Lens Wearer: Multinucleated Giant Cells in the Giemsa Smear Offered a Clue to the Diagnosis. BMC Ophthalmology, 1, 1.

[27] Polcicova, K., Biswas, P.S., Banerjee, K., Wisner, T.W., Rouse, B.T. and Johnson, D.C. (2005) Herpes Keratitis in the Absence of Anterograde Transport of Virus from Sensory Ganglia to the Cornea. Proceedings of the National Academy of Science of the United States of America, 102, 11462-11467. 
Scientific Research Publishing (SCIRP) is one of the largest Open Access journal publishers. It is currently publishing more than 200 open access, online, peer-reviewed journals covering a wide range of academic disciplines. SCIRP serves the worldwide academic communities and contributes to the progress and application of science with its publication.

Other selected journals from SCIRP are listed as below. Submit your manuscript to us via either submit@scirp.org or Online Submission Portal.
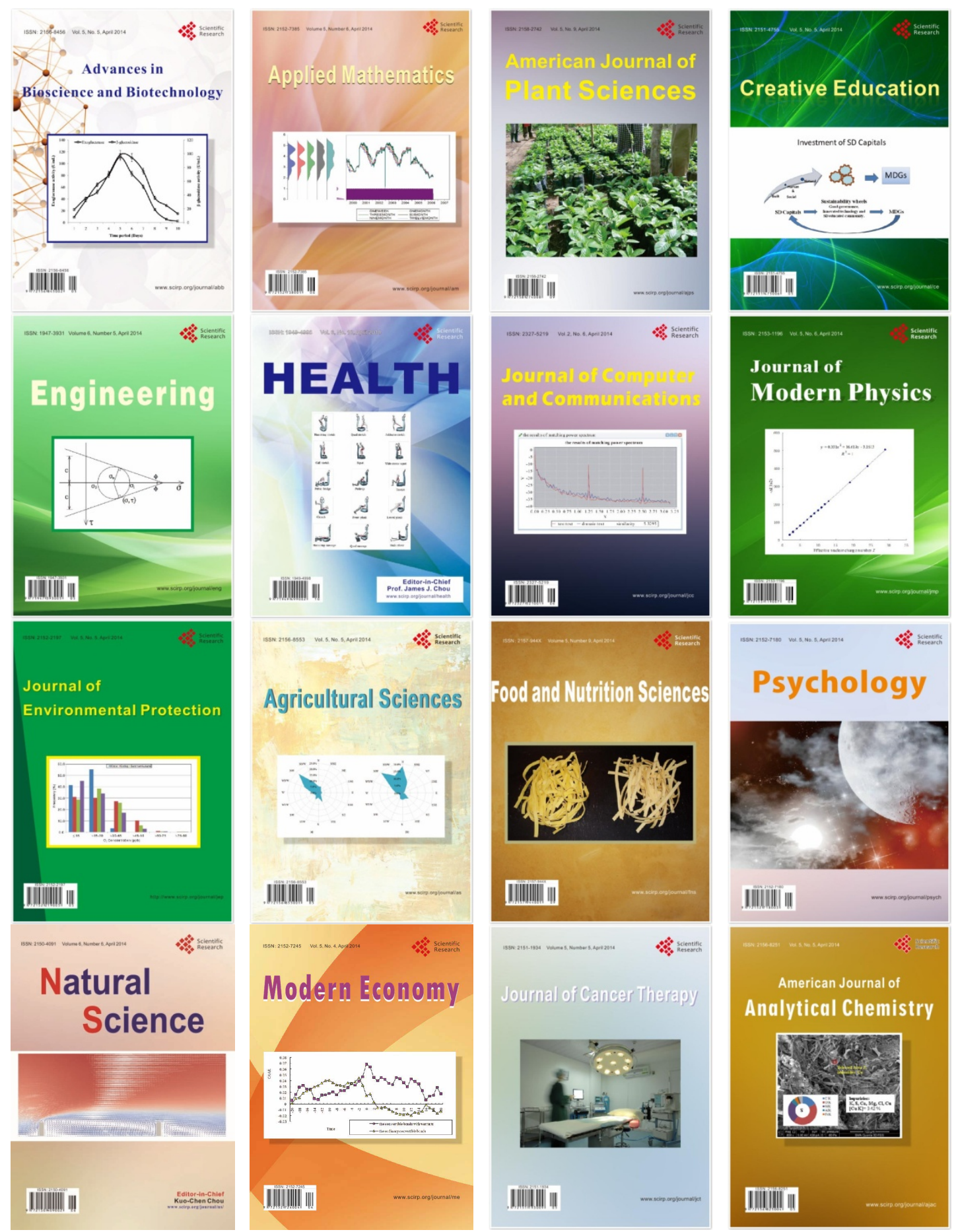